\title{
Applicability of sampling techniques in social sciences
}

\author{
ADEKEYE Adeshola Joseph* and APEH Paulina Eleojo
}

Department of Public Administration, University of Abuja, Nigeria.

Accepted 30 September, 2019

\begin{abstract}
This paper examined the guidelines and procedures for conducting sampling techniques in social sciences. The objective of the study was to empirically demonstrate the application of sampling techniques in the conduct of academic research. A documentary method of data collection in the form of content analysis of empirical data, journal publications, textbooks and projects obtained from the library and internet sources was adopted as research methodology. Also, two completed undergraduate and postgraduate research works were selected as specimens for critical analysis. The research findings revealed that researchers who are supposed to demonstrate the mastery of sampling techniques practically end up defining the concept based on the opinions of various scholars in the field without adopting appropriate sampling techniques. Also, most investigators failed to adopt the right sampling techniques that are capable of addressing the stated research problem or determine the target population and the nature of data collection/analysis of instruments. Similarly, many do not know, when and why a particular sampling technique is suitable for a particular study. The study recommended that researchers should not only study to acquire knowledge on the meaning, types and procedures for the adoption of a sampling technique but they must make frantic efforts to know why, how and when a particular method is the most appropriate for a given study.
\end{abstract}

Keywords: Research, sampling techniques, population, sample size, social sciences.

*Corresponding author. Email: josssy2014@gmail.com. Tel: 8060326463.

\section{INTRODUCTION}

Research is a fact finding mission aimed at discovering the truth or fact about a given phenomenon. It involves data collection, analysis and interpretation of results before drawing conclusion on a particular issue investigated. Therefore, the result obtained from a research work can only be object and result oriented when the procedure adopted is systematic, coherent, scientific and result oriented. Any attempt to a step in the process of conducting research could distort the outcome of the investigation. For instance, the outcome of a research may not be objective, if the appropriate sampling technique is not used. It is always recommended that sampling techniques should be used in the selection of appropriate sample size whenever the research population is too large to be studied as a whole.

Sampling and sample size are crucial issues in pieces of quantitative research which seek to make statistically based generalizations from the study results to the wider world. To generalize in this way, it is essential that the sampling method used and the sample size is appropriate, such that the results are representative, and that the statistics can discern associations or differences within the results of a study. According to Wheelwright and Makridakis (1985), data must be estimated from samples. Optimal sampling methods are fairly well developed in statistics but their methods have not been used extensively in the collection of most data.

Sampling techniques can be generally grouped into probability and non-probability sampling. In a probability sampling, every unit in the population has a chance (greater than zero) of being selected in the sample. Examples include Simple Random Sampling, systematic sampling, stratified sampling, cluster sampling or multistage sampling. Non-probability sampling on the other hand referred situation whereby some elements of the population have no chance of selection or where the probability of selection cannot be accurately determined. It involves the selection of elements based on assumptions regarding the population of interest, which forms the criteria for selection. Selection of elements is non-random, does not allow estimation errors and the conditions give rise to exclusion bias. Examples include 
quota sampling, judgmental or purposive sampling, accidental or convenience sampling, etc. in view of the above foregoing background, this study intends to carry out an empirical application of sampling techniques in Social Sciences.

\section{Statement of the problem}

Research is a process of seeking solutions to a problem, getting more information about it or finding an improved method or way of solving the problem. Research must be planned and methodically carried out for the attainment of its objective. One of the indispensable instruments used in quantitative research is sampling techniques. The inability to use appropriate sampling techniques in arriving at a definite sample size will have far reaching impact on the research findings, conclusion and recommendations. Basically, a sample is any portion of the population selected for study as a representative of the entire population.

A sample may have to be used because of a number of reasons such as: the population is very large, all units of population cannot be reached, some members of the populations are unwilling to give response or cooperate with the research effort, the entire population is not available for data measurement or collection and some may be lost on transit, etc. A decision can be made regarding the characteristics of the entire population using the information derived from the sample. Sampling helps to reduce the survey time and cost of study. The sampling however, must be representative enough to permit the conclusion from the study population. Cost and time constraints would not permit a comprehensive study of all the entire population in a research of such nature. Sampling therefore becomes the best approach to handle researches in Social Sciences.

There has been argument as to what sample size that is appropriate in any research study. According to Macclayton (1998), a good sample is one that gives a fair representative of population. When sampling rules are followed, however, the researcher is assured of minimizing the chances of bias and misrepresentation. However cooper and Emory (1995) argued that "one false belief is that a sample must be large or it is not representative. They went further to argue that though it is often claimed that a sample should be some proportional relationship to the size of the population from which it is drawn, "how large a sample should be is a function of the variation in the population parameters under study and the estimate precision needed by the researcher".

Furthering their argument, the stated that the basic formula for calculating sample size in probability sampling assumes an infinite population; thus, a sample of 100 drawn from a population of 5000 has roughly the same estimating precision as 100 drawn from a population of 200 million. That the most important factor determining the size of a sample needed for estimating a population parameter is the size of the population variance; the larger the sample must be to provide estimation precision (Cooper and Emory, 1995). This argument goes to state that the generally accepted practice of using fixed percentage of $10 \%, 20 \%$ and so on without the knowledge of variance or dispersion in the population is only accepted in the academic especially in Social Sciences as a matter of convenience and not necessarily reflecting the level of precision the researcher want to achieve. This is common in non-probability sampling. This brings us to the question of why sample? Why should we not use the population as the focus of study? In effort to addressing the research problem of this study, the following questions are considered fundamental:

i To what extent is an appropriate sample size needed in Social Sciences?

ii. What are the appropriate qualities of good sampling techniques in Social sciences?

\section{Objectives of the paper}

The objectives of this paper are to:

i. Determine the extent to which an appropriate sample size is needed in Social sciences

ii. Ascertain the appropriate qualities of good sampling techniques in Social sciences

\section{METHODOLOGY}

The secondary method of data collection in the form of content analysis of empirical data, journal publications, text book obtained from the library and internet sources was adopted in this paper. This is not unconnected with the fact that numerous scholars in the field of Social Sciences have made meaningful contributions on the subject matter of sampling techniques. Therefore, assessment of 2 undergraduate and postgraduate research works in the faculty of social sciences was made with a view to making relevant recommendations at the long run.

\section{Conceptual analysis}

\section{Research}

It is common knowledge that the term "research" suffers from the challenges of coming up with all purpose definition of concepts in the field of social and Social sciences. This is not unconnected with the fact that human behaviour is unpredictable. More importantly, the environment and area of orientation of authors play a significant role in articulating their ideas and viewpoints. 
According to Osuala (2001), research can be defined as the process of arriving at dependable solutions to problems through planned and systematic collection, analysis and interpretation of data. In the same vein, Muhammed (2005) conceives research as an organized inquiry that aims at providing information for solving identified problem. He went further to say that research is defined as a systematic and objective search for new knowledge of the subject of study and/or application of knowledge to the solution of a novel problem. However, Kerlinger (1977) considers research from a natural science point of view as "the systematic, controlled, empirical and critical investigation of hypothetical propositions about the presumed relations among natural phenomenon. In the same view, Eboh (1998) defined research as "the process of systematic inquiry by which we increase our knowledge of how things are, why things are the way they are and how they might be changed. It is an intensive and ordered study of a subject aimed at discovering new facts and testing scientific propositions and ideas" (Obasi, 1999).

\section{Population of study}

The concept of research population has been defined in various ways by scholars in the field. Some looked at it from narrow perspectives while others looked at it from broad view points. For instance, Avwokeni (2006) refers to population of study as the "set of all participants that qualify for a study". This means that population refers to only the target group to be studies. However, Popoola (2011) sees population as the "totality of the items or objects under the universe of study. It often connotes all the members of the target of the study as defined by the aims and objectives of the study". Similarly, Nkpa (1997) opined that a population refers to all the elements in a well-defined collection or set of values. Subsequently, Kerlinger (1977) defines population as all members of any well-defined class of people, events or objects. It means therefore that any entity, group or set which constitutes a population must have at least one attribute or characteristic which is common to all of them. Akinade and Owolabo (2009) define it as "the set of observation from which a sample is drawn". Adeniyi et al. (2011) sees it as "the total number of large habitations of people in one geographical area, for example, the population of a country". Parahoo (1997) defines population as "the total number of units from which data can be collected", such as individuals, artifacts, events or organisations. Burns and Grove (2003) describe population as all the elements that meet the criteria for inclusion in a study.

\section{Sample size}

A sample is a subset of the population being studied. It represents the larger population and is used to draw inferences about that population. It is a research technique widely used in the social sciences as a way to gather information about a population without having to measure the entire population. Polit et al. (2001) defines a sample as "a proportion of a population". Holloway and Wheeler (2002) assert that sample size does not influence the importance or quality of the study and note that there are no guidelines in determining sample size in qualitative research. Qualitative researchers do not normally know the number of people in the research beforehand; the sample may change in size and type during research. Sampling goes on until saturation has been achieved, namely no new information is generated (Holloway, 1997). A sample is any portion of the population selected for study as a representative of the entire population. A sample may have to be used because of a number of reasons such as: the population is very large, all units of population cannot be reached, some members of the populations are unwilling to give response or cooperate with the research effort, the entire population is not available for data measurement or collection and some may be lost on transit, etc. A decision can be made regarding the characteristics of the entire population using the information derived from the sample. Sampling helps to reduce the survey time and cost of study. The sampling however, must be representative enough to permit the conclusion from the study population. Cost and time constraints would not permit a comprehensive study of all the entire population in a research of such nature. According to Best and Khan (1995), the ideal sample is large enough to serve as an adequate representative of the population about which the researcher wishes to generalize and small enough to be selected economically in terms of subject availability, expenses in both time and money, the complexity of data analysis etc. Nwana (1981) opines that "if the population is a few hundreds, a $40 \%$ or more sample will do; if many hundreds, a 20\% sample will do; if a few thousands, a $10 \%$ sample will do and if several thousands, a $5 \%$ or less sample will do.

\section{Sampling techniques in social sciences}

Sampling techniques are simply defined as methods of drawing samples from total populations. Burns and Grove (2003) refer to sampling as a process of selecting a group of people, events or behaviour with which to conduct a study. Polit et al. (2001) confirm that in sampling a portion that represents the whole population is selected. Accordingly, sampling techniques in Social Sciences can be grouped into two major classifications; probability and non-probability sampling.

A probability sample is one in which every members of a population has a known assurance or likelihood of being included in a sample to be studied. All probability 
samples must provide a known non-zero chance of selection from each population element, and the simple random sample is considered a special case in which population has a known and equal chance of selection (cooper and Emory, 1995). Probabilistic sample is based on the concept of random selection in a controlled procedure that assure, that each population element is given a known non-zero chance of selection.

In probability sampling, the components of the samples are chosen from the larger population by a process known as randomization. The principle of randomization ensures that all the individual subjects of the larger population have equal chances of being selected and included to be members of the drawn samples. This generates valid samples that are truly representative of the larger populations. This will also permit you to estimate precisely the likelihood of a sample differing from the true population by a given amount. It can be calculated as sampling error. This is an estimate of the extent to which the values of the sample differ from those of the population from which it is drawn. Probability sample clearly shows a technical superiority over non probability sample because a random selection of elements is done and this reduces or eliminates sampling bias. The sampling methods under the Probability sampling are:

i. Stratified sampling: When certain composites characteristics of a target population are known to a researcher and he feels that such characteristics are likely not to be adequately taken care of by a chance factor, then the need for stratified sampling technique arises. Some critical conditions are therefore important in the use of stratified sampling. They include; the awareness of different characteristics of a target population, conviction that such characteristics may not be adequately represented without stratification and the inclusion of different strata. Most populations can be segregated into several mutually exclusive subpopulations or strata. The process by which the sample is constrained to include elements from each of segments is called stratified random sampling. In the case of stratified random sampling, the research population is divided into non-overlapping groups called "strata" before using random methods in selecting the sample size (Obasi, 1999).

ii. Cluster sampling: In a random sample each population element is selected individually. The population can also be divided into groups of elements with some groups randomly selected for the study. This is cluster sampling (Cooper and Emory, 1995). When the population of the study is very large and widely dispersed or spread, it poses administrative problems to use simple random sampling. Therefore, in cluster sampling, the researcher identifies his research interest characteristics and where or in what areas these characteristics exist. If the population is large or the area is widespread, he may decide to zone the area reflecting these characteristics and then random samples from each of the identified zones. The emphasis here is on the characteristics of the sub-group and not on individual. Cluster sampling saves time and resources. It is mostly used in research where there is an urge or desire to study the characteristics of respondents in their natural settings or to ensure geographic representation of noted groups whose special characteristics are of interest to the researcher. When properly done, cluster sampling also provides an unbiased estimate of population parameters.

iii. Multi-stage sampling: This is a further development of the idea of cluster sampling. This technique is meant for big inquiries expending to a considerably large geographical area like an entire country. Under multistage sampling, the first stage may be to select large primary sampling units such as states, then districts, then towns and finally certain families within towns. If the technique of random- sampling is applied at all stages, the sampling procedure is described as multi-stage random sampling and so on (Cooper and Emory, 1995).

iv. Simple random: This is a sampling where every member of the population has equal and independent chance of being selected in the sample to be studied. This equality of chance for each member of the population is the most distinguishing feature of simple random sampling. In simple random sampling, each population element has an equal chance of being selected into the sample. Sample is drawn using random number table/ generator such as computer. This is easy to implement, provided there is an automatic dialing or number generating system. But it has disadvantage that it requires a listing of population elements. It is expensive as it uses large sample size (Cooper and Emory, 1995).

v. Systematic sampling: Systematic sampling involves selecting every nth elements or person from the target population. Here, the population elements are numbered systematically from which the unit is selected. The selection is worked out by dividing the total number of population by the desired sample size. If the population is 500 and 50 , this means out of every 10 names, one would be selected. The major advantage of systematic sampling is its simplicity and flexibility (Cooper and Emory, 1995).

A non-probability sampling on the other hand is called biased sampling or non-random sampling technique. This is because the chances of an element, person, object, event, thing etc. being included in the sample are not the same. Some may have more advantages than the others. It does not involve randomization and therefore may have high sampling error and generalization is limited. According to Parahoo (1997), in non-probability sampling 
researchers use their judgment to select the subjects to be included in the study based on their knowledge of the phenomenon. This is a type of sampling where you do not know the probability of each population element being included in the sample. They are known to generate biased samples that are not truly representative of the target population from which they are drawn. Any sample that is non-valid can encourage errors in findings that cannot be generalized to the total population (Obasi, 1999).

Non-probability sampling uses subjective approach. It is subjective in that the probability of selecting population elements is unknown. But we may use non probability sampling because such a procedure satisfactorily meets the sampling objective. A second reason for choosing non probability sampling over probability sample is cost and kind of conducting probability. Also while probability sampling may be superior in theory, there are breakdown in its application. Even carefully stated random sampling procedure may be subjected to careless application by the people involved.

The commonest non-probability sampling available are:

i. Convenience samples: Here samples are unrestricted. The researchers or field workers have the freedom to choose whoever view they can find. Thus; the name convenience was used. It is likened to what Uyimadu (2005) called accidental sampling. Sample here has no control to ensure precision.

ii. Purposive sampling: It selects individuals or objects on the basis of prior judgment about their relevance to the study (Uyimadu, 2005). This is a non-probability sampling that conforms to certain criteria (Cooper and Emory, 1995). This is necessitated when the researcher is interested in certain specified characteristics. It ensures that only those that meet such required purpose, attributes or characteristics are selected. Two major types of purposive samples can be identified as judgmental and quota sampling. Judgment sampling is appropriate for use (Cooper and Emory, 1995) in early stage of an exploratory study; and also good when one wishes to select a biased group for screening purposes. Quota sampling is used to improve representativeness. Here, the researcher selects a certain number of respondents in proportion to their number in the population, but without randomization. One other method which Cooper and Emory (1995) identified under nonprobability sampling is snowball sampling this is applied where respondents are difficult to identify and are best located through referral networks. Individuals are discovered and may or may not be selected through probability methods. This group is then used to locate others who possess similar characteristics and who, in turn identify others. The snowball gathers subjects as it rolls along.

iii. Accidental sampling: This can be called availability sampling. This is because it makes use of the respondents available at the time. Participation is based on availability. This is very common with pressmen or journalists. They interview or use anybody available at the time.

iv. Captive audience: This is just like an intact class used by the teacher for a research purpose. The generalization should not go beyond the class.

v. Volunteer sampling: This is used when every member of the population cannot comply with the demands of the investigation. Therefore, these individuals who are willing to comply with the demands of the investigations are used. These are the volunteers who are willing and ready to cooperate with the researcher. But this is a biased sample because those volunteers differ from the entire population and from the non-volunteers in many of the characteristics.

\section{Applicability of sampling techniques in social sciences}

The reviewed literatures have shown the most of appropriate way of conducting sampling techniques in social sciences. In the opinion of Macclayton (1998), a good sample is one that gives a fair representative of population .When sampling rules are followed, however, the researcher is assured of minimizing the chances of bias and misrepresentation. Similarly, Ujo (2004) opines that the aim of the researcher always should be to obtain a sample that is as much representative of the population as possible. However, this aim is not always easy to realize in practice owing to several practical limitations such as; time, money and insufficient knowledge of the population. In the face of these obstacles, the researcher has to take some factors into full account while making decisions. These factors include according to Ujo (2004) include:

a. Availability of Fund: The research has to choose such a sample that is possible to obtain with the fund available to him. If obtaining a sample entails a higher cost than the researcher can afford, there is no way he can have such a sample.

b. Population Size: The size of the population has to be taken into account while sampling. Decision to study the entire population or a part of it depends in the population size. The larger the population, the larger the number of elements to be included in the sample.

c. Accessibility: The accessibility of the elements is another important consideration in sampling. The decision to include an element in the sample must take account of the accessibility of such an element.

In view of the above understanding of the procedures guiding sampling techniques, the following 
undergraduates and postgraduate projects are used as specimen in order to empirically demonstrate the applicability of sampling techniques in Social sciences.

\section{Specimen A}

A Master Science Degree thesis titled "Analysis of Women Empowerment in Cassava Production and Processing as a means of Household Poverty status in Kwara State, Nigeria".

In the study, a multistage sampling technique was used in the selection of respondents. The first stage involved the purposive selection of three LGAs where RTEP activities have been implemented. (The reason for their selection was due to their high level of participation in the programme). The second stage was the purposive selection of the villages from the LGAs. The selection was as a result of their high level of involvement in the programme and the third stage involved the random selection of respondents by the use of cards. Two sets of respondents were involved, these include farmers and processors. Twelve percent of the population was used for the study as shown in Table 1.

\section{Analysis of the applicability of sampling technique in Social Sciences}

A glance at the procedures adopted as sampling techniques in the above study revealed that the candidate has a fair knowledge of a good sampling method due to the following reasons:

1. The researcher effectively justified the use of multistage sampling techniques for the study scientifically.

2. The research population and sample size were presented in tabular form for easy identification. Also, the source of the data was equally provided with date.

3 . All the locations of the study area were clearly stated even though government officials who are responsible for the formulation and implementation of empowering women in cassava production and processing were not included in the target population.

However, the following issues were not addressed:

1. There was no single authority quoted for the use of $12 \%$ sample size.

2. Stratified sampling techniques should have been included to demonstrate the characteristics of the population since the study is gender sensitive.

3 . The factors responsible for the choice of the selected three local government and Villages were not clearly explained. This is so because the study failed to provide empirical evidence to demonstrate the level of participation.

4. The use of purpose sampling for the selection of
Table 1. Distribution of respondents in the study area.

\begin{tabular}{llcc}
\hline LGA & Villages & Population & Sample size \\
\hline \multirow{2}{*}{ Oyun } & Erin-lle & 300 & 37 \\
& ljagbo & 230 & 28 \\
\multirow{4}{*}{ Ilorin South } & Ilorin & 500 & 62 \\
& Tanke & 310 & 38 \\
& & & \\
\multirow{5}{*}{ Oke-Ero } & Idofin Odo-Ashe & 150 & 19 \\
& Iloffa & 130 & 15 \\
& Total & 1,625 & 199 \\
\hline
\end{tabular}

Source: Field Survey, 2012.

respondents was not justified. Other sampling techniques could have been more appropriate.

5. In view of the above reasons, we cannot justify whether the adopted sample size represents the entire population. By implication, the findings, summary and recommendations provided by the study may not represent the opinion of the research population.

\section{Specimen B}

In a study conducted for the award of a Bachelor of Science (B.Sc.) degree on a topic titled "The Assessment of the Role of the Economic and Financial Crimes Commission (EFCC) in Combating Corruption in Nigeria between 2005 and 2014, the following population, sample size and sampling technique were used.

The population of study consists of staff of the EFCC Head quarters, Abuja. There is currently 544 staff of the commission at the headquarters in Abuja and 275 staff in the states offices; the states are Oyo, Kogi, Imo, Bauchi, Kaduna, Osun, Kano, Edo, Lagos, Enugu, Sokoto, Adamawa, Benue, Akwa lbom and Rivers state. The Abuja office is the subject of this study. Therefore, the study focused on the 544 staff in the headquarters. The 544 staff strength is spread across 7 departments. These departments are: prosecution, investigation, finance and account, education, public enlightenment, administration and planning research and review department (EFCC Publications Unit, 2014). The population of Abuja residents currently stands at 2.153 million people (Nigerian demographics profile, 2015), which would include students, civil servants, public servants, selfemployed and private business owners.

\section{Sample size and Sampling technique}

The sampling technique employed for the residents of Abuja is Multi-stage Sampling technique. This was considered appropriate because it helps to reduce the population to a manageable size for the study. The 
sample size for the population is calculated thus:

$10 \%$ of $2,153,000=21530$

$10 \%$ of $21530=2153$

$10 \%$ of $2153=215.3$

Hence, the sample size for the residents of Abuja is 215 . However, simple random sampling was also used. For the staff of the EFCC, cluster sampling technique was used; 5 questionnaire instruments were distributed to each department of the EFCC, making a total of 35 questionnaire instruments to the 7 departments. The total sample size of this research work is 250 respondents.

\section{Analysis of the applicability of sampling technique in social sciences}

The adopted sampling technique for the above study is inappropriate. In the first place, the research population was not properly defined. For instance, the population of EFCC staff at the state levels were completely excluded from the study. How then can the sample size be representative of the entire population? Similarly, 215 cannot represent the population 2,153,000. Being that as it may, the source of the research population was not given. The researcher should have used purposive sampling in picking the categories of residents to be sampled. Apart from the non representative nature of the sample size, the use of $10 \%$ in three places is not supported by the opinion of any scholars.

\section{FINDINGS}

a) The reviewed studies above demonstrate the following weaknesses:

1. The researcher was able to state the population of study in specific term instead of only defining the meaning of "population" or using the result of 2006 population census.

2. The researcher arrived at the sample size scientifically through use of $10 \%$ of the research population.

3 . The studies mentioned the number of departments and locations EFCC even though, the figures were not captured.

4. The study selected Abuja Headquarters Office as the unit of the research population with the aim of using the knowledge of inductive reasoning in arriving at logical conclusion.

5. The study failed to justify the reasons and procedures for the use of multi-stage sampling techniques scientifically.

b) The reviewed studies above demonstrate the following weaknesses:
1. The sample size selected failed to pass the tests of fair representative of research population.

2. The researcher failed to use any formular or quote any authorities as a backup for using a particular percentage as a representative of research population.

3 . The studies failed to effectively define the research population of study. Also, there were no sources provided as back-up for the research population

4. Some vital elements of research population were excluded without any fundamental reasons.

\section{CONCLUSION}

This paper empirically demonstrated the applicability of sampling technique in social sciences. The study shows that a sample is any portion of the population selected for study as a representative of the entire population. A sample may have to be used because of a number of reasons such as: the population is very large, all units of population cannot be reached, some members of the populations are unwilling to give response or cooperate with the research effort, the entire population is not available for data measurement or collection and some may be lost on transit, etc. A decision can be made regarding the characteristics of the entire population using the information derived from the sample. Sampling helps to reduce the survey time and cost of study. The sampling however, must be representative enough to permit the conclusion from the study population. Cost and time constraints would not permit a comprehensive study of all the entire population in a research of such nature. Sampling therefore becomes the best approach to handle researches in Social and Social Sciences (SMS). The validity of a sample depends upon two conditions (Cooper and Emory, 1995). They include; accuracy and precisions of estimate. Accuracy refers to the degree to which bias is absent from the sample. An accurate (unbiased) sample is one in which the under-estimators and over estimators are balanced among the members of the sample. A second criterion of a good sample designed is the precision of estimate. Precision is measured by the standard error of estimate, a type of standard deviation measurement; the smaller the standard error of estimate the higher the precision of the sample.

\section{RECOMMENDATIONS}

After thorough assessment of the findings of this paper, the following recommendations are considered fundamental while making decision on the choice of a particular research population, sampling techniques and sample:

1. There is need to determine the accurate research 
population through the use of appropriate sampling techniques. Non-probability sampling techniques are recommended in a situation whereby the study population is infinite or undefined. Also, appropriate formular can be used in reducing the research population to a manageable proportion.

2. The use of particular sampling techniques should be based on the nature of the research population and the objective of the research work. This is necessary because, the use of wrong sampling technique can result into a faulty calculation of sample size.

3. The sample size to be used must be an exact representative of the research population. This is necessary in order to make appropriate generalization based on the result of research findings.

4. The sample size must not be too large or too small. If is too small, the outcome of the study would not be able to represent the opinion of research population. If it is too large, the researcher may not have enough time or adequate resources to administer the research instruments.

5. The selection of sample size through the use of random sampling should be done through the use of sampling with replacement in order to avoid double sampling.

6. Students who intend to use a particular sampling technique should make proper consultation with their supervisors before making final decision on the sample size to be selected. This will go a long way in eliminating sampling error at the end of the study.

\section{REFERENCES}

Adeniyi, A. L., Oyekanmi, A. O., and Tijani, M.O. (2011). Essentials of Business Research Methods. Lagos: CSS Bookshops Limited.

Akinade, E. A., and Owolabi, T. (2009). Research Method: A Pragmatic Approach for Social Sciences, Behavioural Sciences and Education. Lagos: Connel Publication.

Avwokeni, J. A. (2006). Research Methods: Process, Evaluation and Critique. Portharcourt: Unicampus Tutoria Services.

Best, J. W., and Khan, J. V. (1995). Research in Education. New Delhi Prentice-Hall of India.

Burns, N., and Grove, S. K. (2003). Understanding nursing research. 3rd Ed. Philadelphia: Saunders Company.

Cooper, D. K., and Emory, C. W. (1995). Business Research Methods. 4th Ed. Burbidge Illinois. Leedy, P.D. (1997) Practical Research: Planning and Design. New Jersey Merril.

Eboh, K. G. (1998). Social and Economic Research Principles and Methods. Lagos: Academic Publications and Development Resources Ltd.

Holloway, I., and Wheeler, S. (2002). Qualitative Research in Nursing. Oxford: Blackwell Science. Keith, L. A., and Gubelling, C. E. (1975). Introduction to Business Enterprise. 4th Ed. McGraw-Hill Kogakusha.

Kerlinger, F. N. (1977). Foundations of Behavioural Science. Holt, Rinehart and Winston, Inc.

Macclayton, W. D. (1998). Research Methods. An Unpublished Lecture Material. RSUST, Port Harcourt.
Muhammed, I. A. (2005). Nature and Significance of Social Research. Research Methodology in the Social and Management Sciences. A Publication of Public Administration Department, University of Abuja. Abuja: Joyce Publishers.

Nkpa, N. (1997). Educational Research for Modern Scholars. Enugu: Fourth Dimension Publishers.

Nwana, O. C. (1981). Introduction of Education Research. Ibadan: Heinemann Educational Books Ltd.

Obasi. I. N. (1999). Research Methodology in Political Science. Enugu: Academic Publishing Company.

Osuala, E. C. (2001). Introduction to Research Methodology. $3^{\text {rd }}$ Ed. Onitsha: Africana-Feb. Publishers, Ltd.

Parahoo, K. (1997). Nursing research: Principles, process and issues. London: MacMillan Press.

Polit, D., Hungler, B., and Beck, C. (2001). Essentials of Nursing Research. 5th Ed. Philadelphia: Lippincott Williams \& Wilkins.

Popoola, S. O. (2011). Research Methodologies in Library and Information Science. A paper presented at a training workshop on building research capacity for Library and Information Science professionals, Organized by the Association, Ogun State Chapter, held at Covenant University, Ota, on $18^{\text {th }}-22^{\text {nd }}$ September.

Ujo, A. A. (2004). Social Research in Nigeria (Understanding). Joyce Graphic Printer and publication: Kaduna.

Uyimadu S. O. (2005). Research Methods and Procedures in the Social Sciences Social Science, Education, Science and Engineering. Harmony Books, Benin City.

Wheelwright, S. C., and Makridakis, S. (1985). Forecasting Methods for Management. 4th Edition, New York: John Wiley and Sons.
Citation: Adekeye, A. J., and Apeh, P. E. (2019). Applicability of sampling techniques in social sciences. Net Journal of Social Sciences, 7(4): 101-108. 